\title{
Patient and physician related factors of adherence to evidence based guidelines in diabetes mellitus type 2, cardiovascular disease and prevention: a cross sectional study
}

\author{
Johanna Fürthauer ${ }^{1,2^{*}}$, Maria Flamm²,3 and Andreas Sönnichsen ${ }^{1}$
}

\begin{abstract}
Background: Patients do not always receive guideline-adherent therapy, yet little is known about the underlying causes on the patients' side. We quantified non-guideline-adherent treatment of chronic diseases (diabetes mellitus, hypertension, cardiovascular disease, heart failure, atrial fibrillation) in primary care and analysed the causes from the physician's as well as the patient's view.

Methods: With the intention to analyze the frequency and causes of non-guideline-adherent treatment of patients with chronic diseases, we drew a random sample of 124 general practitioners (GP) in Salzburg, Austria, of which 58 (46.8\%) participated. In the participating GP surgeries, we consecutively recruited 501 patients with at least one of the target-diseases and checked the guideline conformity of treatment using 9 quality indicators. We then interviewed the patients as well as the general practitioners regarding factors affecting deviation from guideline recommendations.

Results: Of the 501 patients, a total of 1224 quality indicators could be analysed. Non-adherence to guideline recommendations were present in $16.8 \%(n=205,95 \% \mathrm{Cl} 14.7$ to $18.8 \%)$ of all quality indicators. In $61.5 \%$ of these cases ( $n=126,95 \% \mathrm{Cl} 53.0$ to $70.0 \%$ ) the treatment was wrongly judged as not recommended by the physicians. In $10.2 \%$ ( $n=21,95 \% \mathrm{Cl} 0$ to $23.2 \%$ ) physicians attributed non-adherence to patient's non-compliance, and in 10.7\% ( $n=22,95 \% \mathrm{Cl} 0$ to $23.7 \%)$ to an adverse drug event, whereas only $5.4 \%(n=11,95 \% \mathrm{Cl} 0$ to $18.7 \%)$ of nonadherence was related to an adverse drug event reported by the patients. Patients were unaware regarding the reason for non-adherent therapy in $64.4 \%(n=132,95 \% \mathrm{Cl} 56.2$ to $72.6 \%)$ of the quality indicators. In $20.0 \%(n=41$, 95\% Cl 7.8 to $32.2 \%$ ) patients regarded a drug as not needed.

Conclusions: Guideline adherence in chronic care was relatively good in our study sample, but still leaving room for improvement. Physicians' lack of knowledge and patients' lack of awareness account for about $70 \%$ of non-adherence, indicating the necessity to improve physician education, and patient involvement. In about 30\% of the quality indicators not fulfilled, non-adherence is due to other reasons like adverse drug events or patients not willing to take a recommended drug.
\end{abstract}

Keywords: Non-adherence, Cardiovascular disease, Prevention, Patient adherence, Guideline adherence

\footnotetext{
* Correspondence: johanna.fuerthauer@pmu.ac.at

'Institute of General Practice and Family Medicine, University of Witten/

Herdecke, Alfred-Herrhausen-Str. 50, Witten 58448, Germany

${ }^{2}$ Institute of General Practice, Family Medicine and Preventive Medicine,

Paracelsus Medical University, Strubergasse 21, Salzburg 5020, Austria

Full list of author information is available at the end of the article
} 


\section{Background}

To decrease the burden of chronic diseases, treatment guidelines have been developed based on current best evidence from large clinical trials. In Austria, the EbMGuidelines [1] are most widely used. However, we know from various studies that guidelines are not always applied and followed [2-5]. The barriers to guideline-adherence have been studied quite extensively concerning the physician's point of view, mainly in qualitative [6-10], but also in quantitative studies. A systematic review of studies addressing physicians' barriers to guideline adherence, identified physicians' lack of awareness of a guideline's existence and lack of familiarity with the guideline as the leading causes of deviation from recommended therapy [11]. Thus ample data exist on the epidemiology of guideline adherence as well as physicians' barriers to guideline implementation, leading to the assumption that physicians are generally responsible for non-adherence. Based on this assumption, the quality and outcomes framework has been designed in the UK and proven to enhance guideline-adherence substantially [12].

Besides non-adherence due to lack of awareness and lack of familiarity, there may be other reasons for not prescribing a drug which are related to the individual patient, his values, and preferences. Much less is known about patient-related causes of non-adherence to the guidelines. A recent study identified patient ability and patient preferences as potential barriers, based on a survey of GP perceptions [13], but we are not told how patients themselves perceive these barriers, and we could not identify a single study looking at both patient- and physician-related causes of non-adherence at the same time.

We therefore conducted a cross-sectional study in the primary care setting to detect and quantify non-guidelineadherent treatment of chronic diseases, and to quantitatively analyse the causes of non-adherence from the physician's as well as the patient's point of view. Since cardiovascular disease represents the major cause of morbidity and death [14], and demographic changes may lead to a further rise in prevalence, we decided to concentrate particularly on these diseases (cardiovascular disease, heart failure, atrial fibrillation) and the most important risk factors (diabetes mellitus type 2 and hypertension).

\section{Methods}

We obtained a complete list of all 200 general practitioners (GPs) under contract with statutory public health insurance in four districts (Salzburg city, Pongau, Tennengau, Flachgau) of the province of Salzburg, Austria. GPs were randomly listed by an electronic randomisation process. Following this order, physicians were asked to participate in the study to obtain a random sample of 58 GPs, corresponding to the study duration of three months (58 consecutive working days from January to April 2011). Each surgery was audited for one day by the principal researcher (JF). On that day, all consecutive patients with at least one of the target diseases or risk factors (arterial hypertension, diabetes mellitus type 2, heart failure, atrial fibrillation, cardiovascular disease) were asked to participate in the study. In Austria, patients can freely choose their GP and usually visit the surgery without arranging appointments. Thus the patient sample represents a random consecutive selection. After signing informed consent, the patients were assessed via a structured case report form (CRF). We collected demographic data, smoking status, patient's diagnoses regarding chronic diseases, medication and medical data (from the surgery's patient health record). A detailed description of patient data is presented in Table 1.

We used 9 quality indicators (QI) based on the EbMguidelines most commonly applied in Austria [1] to determine guideline-adherence regarding the treatment of the target-diseases mentioned above. The QIs are described in detail in Table 2 .

Patients with hypertension were considered to be inadequately treated if they did not reach the target of 140 $\mathrm{mmHg}$ in multiple measurements or 24-hour-monitoring, or if a single measurement was above $160 \mathrm{mmHg}$.

Since we only evaluated cardiovascular diseases as mentioned, it was not possible to evaluate all contraindications for each particular drug. As we collected patients' creatinine values, it was possible to calculate the GFR and to define a GFR lower than $60 \mathrm{ml} / \mathrm{min}$ as an exclusion criterion for metformin therapy. All other more or less weak contraindications, e.g. COPD as a contraindication for $\beta$-blockers in the treatment of patients after myocardial infarction, were not specifically obtained and were only recorded as non-specified "contraindications" in our clinical report form (CRF; see Table 3).

We then interviewed the patient and the physician independently about underlying reasons for non-adherent treatment, using a structured CRF. The reasons given by patients and physicians are presented in Table 3. The category "other" was offered but it was possible to transfer each answer to one of the other offered causes. All data were pseudonymised and recorded in pre-specified case report forms and then transferred to $\mathrm{IBM}^{\circledR} \operatorname{SPSS}^{\circledR}$ Statistics 19.0 for further analysis.

The study was carried out in compliance with the Declaration of Helsinki and with Austrian data protection legislation. Ethics approval has been obtained from the ethics committee of the federal state of Salzburg, Austria.

\section{Results}

We had to randomly select 124 of the 200 GPs eligible to obtain a sample of 58 GPs willing to participate (response rate $46.8 \%)$. In these 58 GP surgeries 526 consecutive patients were invited to participate in the study. 501 of these patients (95.3\%) gave informed consent and 
Table 1 Data collected via case report form (CRF)

\begin{tabular}{|c|c|c|}
\hline \multicolumn{3}{|c|}{ Data collected via case report form (CRF) } \\
\hline \multirow[t]{5}{*}{ Demographic data } & Age & \\
\hline & Sex & \\
\hline & Height & \\
\hline & Weight & \\
\hline & Smoking status & \\
\hline \multirow[t]{6}{*}{ Chronic diseases } & Diabetes mellitus type 2 & \pm micro- or macro-vascular complications \\
\hline & Arterial hypertension & \\
\hline & Atrial fibrillation & \\
\hline & Heart failure & (including NYHA-stage) \\
\hline & Cardiovascular diseases & $\begin{array}{l}\text { Myocardial infarction, aortocoronary bypass or stenting, angina } \\
\text { pectoris and coronary stenosis*, peripheral arterial occlusive } \\
\text { disease, peripheral arterial thromboembolism }\end{array}$ \\
\hline & Cerebrovascular diseases & $\begin{array}{l}\text { Stroke, transitory ischemic attack, carotid endarterectomy } \\
\text { or stenting }\end{array}$ \\
\hline \multirow[t]{5}{*}{ Medication } & Oral antidiabetics & Metformin \\
\hline & Antihypertensive drugs & $\begin{array}{l}\text { Inhibitors of the renin-angiotensin-aldosterone system (RAAS), } \\
\text { diuretics (thiazides, furosemide) calcium channel blockers, } \\
\text { beta-blockers }\end{array}$ \\
\hline & Platelet aggregation Inhibitors & Acetylsalicylic acid, clopidogrel, prasugrel \\
\hline & Anticoagulants & Vitamine-K-antagonists \\
\hline & Lipid lowering therapy & Statins \\
\hline \multirow[t]{5}{*}{$\begin{array}{l}\text { Medical data (via patient's } \\
\text { health records) }\end{array}$} & Blood pressure & $\begin{array}{l}\text { Singular measurement, multiple self-measurements or 24-h } \\
\text { record if available }\end{array}$ \\
\hline & $\mathrm{HbA}_{1 \mathrm{c}}$ & \\
\hline & Creatinine level & \\
\hline & International normalized ratio & In case of oral anticoagulation \\
\hline & Total serum cholesterol, LDL and HDL levels & \\
\hline
\end{tabular}

were finally included in the analyses, corresponding to a mean of $8.6 \pm 5.3$ (SD) patients per surgery. These patients had a total number of 922 target diseases with a total number of 1224 QIs analysed (three QIs for heart failure, three QIs for cardiovascular disease, and one QI for each of the other diseases). Descriptive data of all patients are depicted in Table 4.

The prevalence of the targeted chronic diseases within our cohort and the percentage of patients not treated according to the guidelines using the QIs defined above

Table 2 List of quality indicators (QIs)

\begin{tabular}{|c|c|c|}
\hline QI & Medication & Threshold or indication \\
\hline 1 & $\begin{array}{l}\text { inhibitors of the renin-angiotensin-aldosterone system (RAAS; ACE-I } \\
\text { or ARB or Renin-Inhibitors [RI]), calcium channel blockers, } \beta \text {-blockers } \\
\text { or thiazides or a combination of these drugs }\end{array}$ & $\begin{array}{l}\text { Arterial hypertension with BP above target (systolic BP >140 mmHg } \\
\text { in multiple or } 24 \mathrm{~h} \text {-measurements or }>160 \mathrm{mmHg} \text { in single } \\
\text { measurement) }\end{array}$ \\
\hline 2 & Metformin & Diabetes mellitus type $2\left(\mathrm{HbA}_{1 \mathrm{c}}>53 \mathrm{mmol} / \mathrm{mol}(7 \%)\right)$ \\
\hline 3 & $\beta$-blocker & Chronic heart failure (any stage) \\
\hline 4 & RAAS-I & Chronic heart failure (any stage) \\
\hline 5 & Aldosterone antagonist & Chronic heart failure, NYHA-stage III or IV \\
\hline 6 & Oral anticoagulation & Atrial fibrillation \\
\hline 7 & Statin & $\begin{array}{l}\text { Any cardiovascular disease (coronary heart disease, cerebrovascular } \\
\text { disease, peripheral vascular disease) }\end{array}$ \\
\hline 8 & Platelet aggregation inhibitor & Any cardiovascular disease \\
\hline 9 & $\beta$-blocker & History of myocardial infarction \\
\hline
\end{tabular}


Table 3 Possible causes of non-adherence to the guidelines evaluated and transferral for analysis

\begin{tabular}{|c|c|c|c|}
\hline Patient answer & Transferred to & Physician answer & Transferred to \\
\hline I do not know & I do not know & I do not know & Falsely not indicated GP \\
\hline I do not need it & I do not need it & Not indicated & \\
\hline \multirow[t]{3}{*}{ I do not want it } & I do not want it & Noncompliance & Noncompliance \\
\hline & & Avoidance of polypharmacy & Avoidance of polypharmacy \\
\hline & & Specialist did not prescribe it & Falsely not indicated $\mathrm{s} / \mathrm{h}^{*}$ \\
\hline \multirow[t]{4}{*}{ I do not take it any more } & Adverse drug event & Contraindication & Contraindication \\
\hline & Falsely discontinued $^{\dagger}$ & Patient does not take it anymore & Adverse drug event \\
\hline & & & Falsely discontinued $^{+}$ \\
\hline & (or one of the above) & & (or one of the above) \\
\hline Other & Allocation to one of the above & Other & Allocation to one of the above \\
\hline
\end{tabular}

* Falsely not indicated specialist / hospital (when a certain therapy was not initiated or recommended by specialists or physicians in the hospital, and the GP adhered to this recommendation even though in fact there was an indication for the drug).

${ }^{\dagger}$ Defined as a stop of treatment triggered by the physician despite guidelines recommending a continuation of the therapy (e.g. discontinuation of statin therapy after reaching target values for LDL-cholesterol which then rose above target again).

are shown in Table 5. In 185 (36.9\%) of all patients, at least one QI was not fulfilled. Overall, guideline adherence was not given in $16.8 \%$ (95\% CI 14.7 to $18.8 \%$ ) of all QIs. The distribution of possible causes of nonadherent therapy is shown in Figure 1.

We performed a detailed analysis of underlying causes for non-guideline-adherent treatment referring to each target diagnosis and QI. The results of this analysis are presented in Table 6.

Arterial hypertension was present in 424 patients (84.6\%). 76 patients (17.9\%) had blood pressure measurements above target (QI 1). A combination of up to four antihypertensive drugs is recommended to reach optimal blood pressure levels. Adequate combination therapy of four antihypertensive drugs was prescribed in only 7 of the patients with blood pressure above target (9.2\%). The causes of not fulfilling QI 1 in the remaining 69 patients $(90.8 \%)$ are listed in Table 6 . Nineteen $(27.5 \%$ of all) of them were treated with a three-drug combination.

The study cohort included 174 patients with diabetes mellitus type 2 , of whom 64 (36.8\% of all) did not receive metformin (QI 2). Thirty-two had a contraindication for metformin (glomerular filtration rate [GFR] $</=60 \mathrm{ml} / \mathrm{min}$, using the Cockroft-Gault-formula). We

Table 4 Descriptive data of all patients (mean \pm standard deviation)

\begin{tabular}{lcc}
\hline \multicolumn{3}{c}{ Descriptive data of all patients } \\
\hline Male total $\mathrm{n}$ & 251 & $(50.1 \%)$ \\
Male smokers (\%) & 15.1 & \\
Female total $\mathrm{n}$ & 250 & $(49.9 \%)$ \\
Female smokers (\%) & 9.6 & \\
Age (years $\pm \mathrm{SD})$ & 69.5 & \pm 10.9 \\
$\mathrm{BMl}\left(\mathrm{kg} / \mathrm{m}^{2} \pm \mathrm{SD}\right)$ & 28.1 & \pm 4.8 \\
\hline
\end{tabular}

could not obtain a creatinine value for two of the patients. Nineteen of the remaining 30 patients had an $\mathrm{HbA}_{1 \mathrm{c}}$ value of less than $53 \mathrm{mmol} / \mathrm{mol}$ (7\%), and for three patients, we could not obtain an $\mathrm{HbA}_{1 \mathrm{c}}$ value. All in all, QI 2 was not fulfilled in only eight (4.6\%) of all patients with diabetes mellitus type 2 . The causes of deviation from the guideline are listed in Table 6.

We found 41 patients with heart failure in our cohort, 15 (36.6\% of all) did not receive any $\beta$-blocker (QI 3) and 8 (19.5\% of all) were not treated with an RAAS-inhibitor (QI 4), as would have been recommended. Seven $(17.1 \%$ of all) patients had a NYHA stage of III or more. The NYHA stage was not definable in 3 patients, so QI 5 was not fulfilled only in 4 patients ( $9.8 \%$ of all). The causes for guideline deviation are listed in Table 6.

Atrial fibrillation was present in 106 patients, of whom 15 (14.0\% of all) were not treated with oral anticoagulants as defined in QI 6. The reasons for non-adherence are presented in Table 6.

The diagnosis of any cardiovascular disease was present in 177 patients. Fifty-three (29.9\%) patients were not prescribed any statin (QI 7). Two of them were treated with a fibrate only, and one with ezetimib only. The reasons for not receiving a statin or any lipid-lowering treatment as defined in QI 7 are listed in Table 6.

Furthermore, $53(29.9 \%)$ of the patients with cardiovascular disease did not take platelet aggregation inhibitors (acetylsalicylic acid or clopidogrel or prasugrel) in accordance with QI 8. As a meta-analysis of randomised trials showed that the combination of platelet aggregation inhibitors and oral anticoagulants in patients with atrial fibrillation does not have any additive benefit but carries a higher risk for bleeding [15], we considered oral anticoagulants an acceptable reason to discontinue antiplatelet-therapy. This was the case in 41 patients, so only $12(6.8 \%)$ were not treated as recommended by the 
Table 5 Diagnoses with numbers of QIs and QIs revealing non-adherence to the guidelines

\begin{tabular}{|c|c|c|c|c|}
\hline Diagnosis & $\begin{array}{l}\mathrm{n} \text { of cases with diagnosis } \\
\text { (number of QIs) }\end{array}$ & $\begin{array}{c}n \text { of Qls revealing } \\
\text { non-adherent treatment }\end{array}$ & $\%$ Qls & $\begin{array}{l}\text { on-adheren } \\
5 \% \mathrm{Cl})\end{array}$ \\
\hline Arterial hypertension & $424(424)$ & 69 & 16.3 & $(12.8-19.9)$ \\
\hline Diabetes mellitus type 2 & $174(174)$ & 8 & 4.6 & $(1.5-7.7)$ \\
\hline Heart failure & $41(89)$ & 27 & 30.3 & $(20.8-39.9)$ \\
\hline$\beta$-Blocker & $41(41)$ & 15 & 36.6 & $(21.8-51.3)$ \\
\hline RAAS-I & $41(41)$ & 8 & 19.5 & $(7.4-31.6)$ \\
\hline Aldo-A in NYHA III/IV & $7(7)$ & 4 & 57.1 & $(20.5-93.8)$ \\
\hline Atrial fibrillation & $106(106)$ & 15 & 14.2 & $(7.5-20.8)$ \\
\hline Cardiovascular disease & $177(431)$ & 86 & 20.0 & $(16.2-23.7)$ \\
\hline Statin & $177(177)$ & 53 & 29.9 & $(23.2-36.7)$ \\
\hline Platelet aggregation inhibitors & $177(177)$ & 12 & 6.8 & $(3.1-10.5)$ \\
\hline$\beta$-blocker after myocardial infarction & $77(77)$ & 21 & 27.3 & $(17.3-37.2)$ \\
\hline Total* & 922 (1224) & 205 & 16.8 & $(14.7-18.8)$ \\
\hline
\end{tabular}

* The number of diagnoses exceeds the number of patients as many subjects had more than one of the target diagnoses.

guidelines (QI 8). The causes of non-adherence to the guidelines are listed in Table 6.

A history of myocardial infarction was present in 77 of the 177 patients with cardiovascular disease, and 21 (27.3\% of all patients with myocardial infarction) of them were not on $\beta$-blocking treatment as defined in QI 9. The causes for non-adherence are listed in Table 6.

\section{Discussion}

We found obvious deficits in care regarding guideline adherent drug therapy for hypertension, diabetes mellitus type two, heart failure, atrial fibrillation and secondary prevention in cardiovascular diseases. About a sixth of all quality indicators in our study were not fulfilled according to current guideline recommendations. In more than half

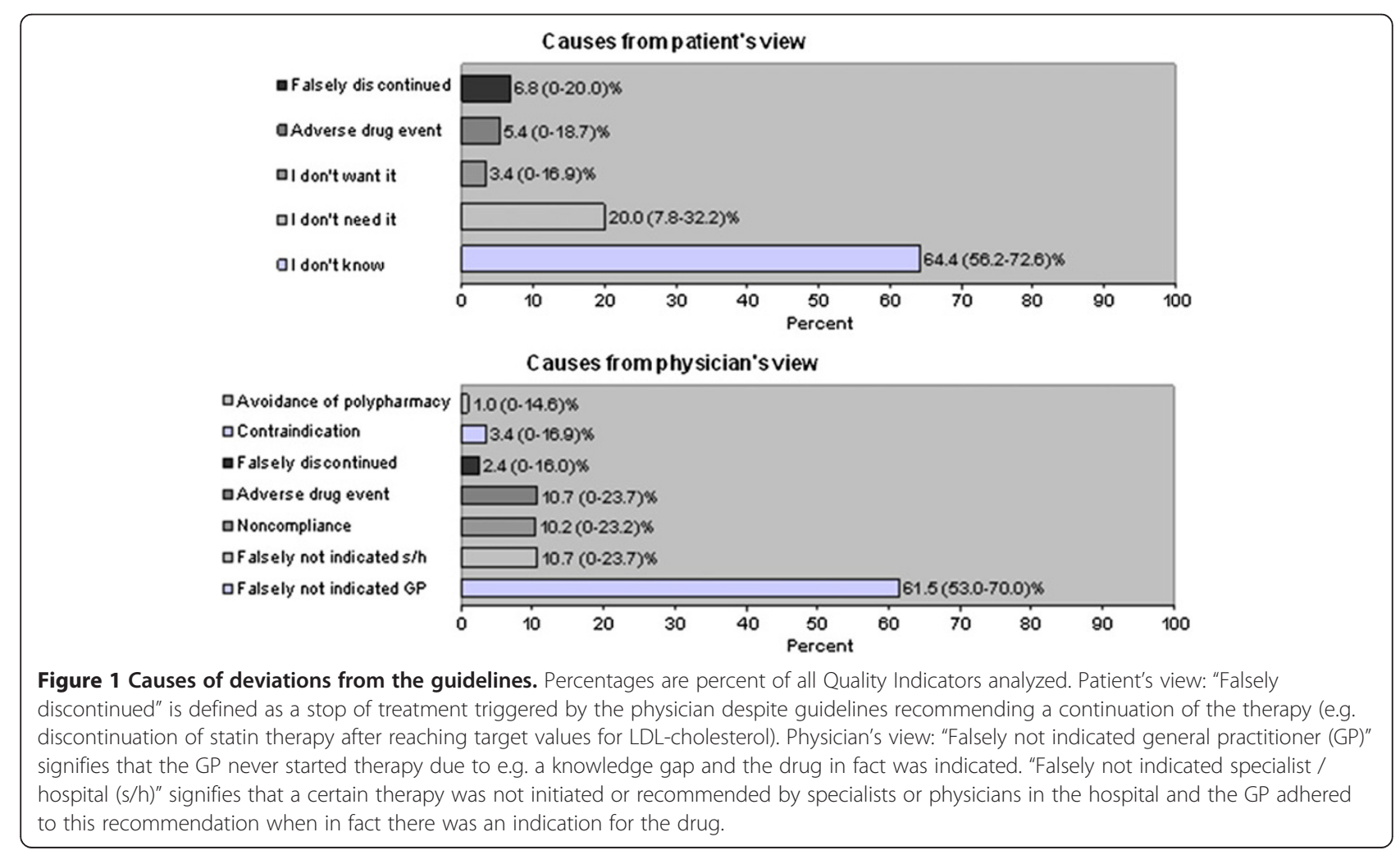


Table 6 Causes of deviation from guidelines for every drug and diagnosis in \%

\begin{tabular}{|c|c|c|c|c|c|c|c|c|c|}
\hline \multicolumn{10}{|c|}{ Causes of deviation from guidelines from patient's view } \\
\hline $\mathrm{n}$ & 69 & 8 & 15 & 8 & 4 & 15 & 53 & 12 & 21 \\
\hline Reason (in \%) & Anti-HT & Metformin & HF: $\beta B$ & HF: RAAS-I & HF: AldoA & AF: OAK & CVD: statin & CVD: antipltlt & $M C l: \beta B$ \\
\hline I don't know & 91.3 & 50.0 & 60.0 & 62.5 & 75.0 & 66.7 & 30.2 & 50.0 & 76.2 \\
\hline I don't need it & 2.9 & 25.0 & 26.7 & 37.5 & 25.0 & & 45.3 & 25.0 & 9.5 \\
\hline I don't want it & & 12.5 & & & & 13.3 & 7.5 & & \\
\hline Adverse drug event & 4.3 & & 13.3 & & & 6.7 & 7.5 & & 4.8 \\
\hline Falsely discontinued & 1.4 & 12.5 & & & & 13.3 & 9.4 & 25.0 & 9.5 \\
\hline \multicolumn{10}{|c|}{ Causes of deviation from guidelines from physician's view } \\
\hline $\mathbf{n}$ & 69 & 8 & 15 & 8 & 4 & 15 & 53 & 12 & 21 \\
\hline Reason (in \%) & Anti-HT & Metformin & HF: $\beta B$ & HF: RAAS-I & HF: AldoA & AF: OAK & CVD: statin & CVD: PAI & $M C l: \beta B$ \\
\hline Falsely not indicated GP & 78.3 & 37.5 & 80.0 & 62.5 & 50.0 & 33.3 & 56.6 & 33.3 & 52.4 \\
\hline Falsely not indicated $s / h$ & 8.7 & 12.5 & 6.7 & 25.0 & 25.0 & 6.7 & 7.5 & 8.3 & 23.8 \\
\hline Noncompliance & 2.9 & 25.0 & & & & 20.0 & 17.0 & 25.0 & 9.5 \\
\hline Adverse drug event & 8.7 & 25.0 & 6.7 & 12.5 & 25.0 & 6.7 & 11.3 & 25.0 & 4.8 \\
\hline Falsely discontinued & 1.4 & & 6.7 & & & 6.7 & 3.8 & & \\
\hline Contraindication & & & & & & 26.7 & & 8.3 & 9.5 \\
\hline Avoidance of polypharmacy & & & & & & & 3.8 & & \\
\hline
\end{tabular}

Summation does not add up to $100 \%$ due to rounding error.

Anti-HT: antihypertensive medication (RAAS-inhibitor or thiazide or calcium channel blocker or $\beta$-blocker).

Metformin: metformin in diabetes mellitus type 2 patients.

$\mathrm{HF}=$ heart failure.

$\beta B$ : beta adrenoceptor blocker.

RAAS-I: inhibitor of the renin-angiotensin-aldosterone system.

AldoA: aldosterone antagonist.

$\mathrm{AF}=$ atrial fibrillation.

OAK: oral anticoagulation.

CVD = cardiovascular disease.

PAl: platelet aggregation inhibitor (acetylsalicylic acid or clopidogrel/prasugrel). $\mathrm{MCl}=$ myocardial infarction.

of these quality indicators the patients did not know why they were not prescribed a particular drug, thus making us look at the physician as the one responsible for nonadherence. The most frequent reason for physicians to deviate from guideline recommendations was that they falsely assumed that a certain prescription was not indicated or necessary.

There are several possible explanations for the fact that the treatment of patients is not always consistent with evidence based recommendations. According to our study, the most important cause appears to be the physician not providing a particular treatment. This may be due to physicians' lack of awareness regarding the existence of a guideline, or lack of familiarity with a guideline, as has been shown by Cabana et al. [11]. However, non-adherence may also be caused by a deliberate decision to counteract the guideline with which the physician may not agree, in general or for a particular patient.

Even though the GP appears to be the main cause of non-adherence to the guidelines, our study clearly shows that other reasons are involved in at least one third of all quality indicators.
Of the non-GP-related causes, adverse drug events and non-compliance appear to be the most important. In chronic care, GPs are confronted with the problem that they have to keep the patient compliant over a long period of time, and that any drug treatment has to match up to other health goals and is influenced by psychosocial problems [16]. Chapman and co-authors found a sharp decline in drug-adherence to lipid and blood pressure lowering drugs to only $36 \%$ within one year, with the greatest drop occurring in the first three months [17]. The factors determining compliance are manifold: Health education appears to play a crucial role, but other patient specific factors like race, ethnicity, or education are also important [18]. Sometimes patients do not seem to be aware of their illness, or they accept their chronic disease symptoms as normal, e.g. as a result of ageing. Thus, more than half of the patients with heart failure reported their health to be good even though nearly half of them could not walk a quarter of a mile [5]. Another problem may be that many drug effects in cardiovascular prevention are hardly noticeable to the patient so that the importance of the medication 
remains unrecognized. Patients' fears of adverse drug reactions certainly also play a role in non-adherence to recommended treatments. Moreover, insufficient communication including incomplete patient's history taking, conflicting information, neglected disagreements, or a disturbed relationship between the patient and the physician may cause non-adherence or non-compliance [19].

The fact that about two thirds of the patients did not know why they do not receive a recommended drug points out a significant information deficit. While we would not expect all patients to wish to be informed about treatment options, there appears to exist sufficient evidence that most patients would prefer to be involved in evidence based treatment decisions [20]. From our study we cannot distinguish whether the information deficit is due to a lack of communication between physician and patient, or to the patient not wanting to be involved. Looking at one of the leading models for shared decision making it takes both the physician's willingness to share information as well as the patient's desire to be informed [21], and we conclude from our study that it seems unlikely that about two thirds of the patients do not want to know about guideline-adherent, evidencebased treatment choices.

About $20 \%$ of the patients in our study stated that they do not need a drug they should in fact receive. This might reflect certain knowledge deficits regarding present diseases or risk factors.

Although our study reveals important insights regarding the causes of non-adherence to guideline recommendations, some limitations have to be considered. A major weakness of our study is that the sample size is fairly small. This especially limits the explanatory power of the detailed analysis of single diseases, and even the power of the combined data presented in Figure 1 cannot be considered sufficient due to large confidence intervals reaching zero on the left side.

Even though we chose a random sample of physicians, our study may be biased by a response rate of only $50 \%$ on the physician level. On the other hand, this response rate is quite usual in studies involving primary care physicians. The systematic review of Cabana et al. reports a median response rate of $54.5 \%$ for studies investigating physicians' lack of awareness as one of the barriers to guideline adherence [11].

It may be assumed that rather motivated physicians who already provide higher quality service to their patients are more likely to participate in a study of quality analysis. But as our main goal in this study was not to quantitatively analyse non-adherence, but rather differentiate the possible reasons for non-adherence, we believe our data to be quite representative.

We visited each general practitioner only one day and included only patients that consulted their doctor at that time. This may bias our results as well, as one may assume that less compliant patients tend to visit their physician only at rare intervals. We tried to overcome this problem by also including patients coming to the surgery only to pick up a prescription.

We used a narrow set of only process quality indicators to judge guideline adherence in drug therapy. This may also be considered a weakness of our study. In diabetes mellitus type 2, for instance, it has been demonstrated that there is insufficient evidence for many widely used quality indicators regarding their predictive power for clinically relevant outcomes [22]. This appears to be a general problem of using quality indicators, and is not specific to our study.

Last not least our structured interview technique could only obtain categorical data on possible reasons for non-adherence to evidence based guidelines. An indepth qualitative analysis of individual patients' reasons for not taking a drug or physicians' reasons for not prescribing it would be highly desirable and warrants further research.

The strengths of our study are that we examined a representative sample of consecutive patients from both rural and urban areas, and we included all major diseases affecting the cardiovascular system. So far very little is known about the causes of non-adherence to guideline recommended therapy on the patient's side, and thus this study provides data inspiring further research to improve guideline-adherence in chronic care.

\section{Conclusion}

Overall, about $15 \%$ of all QI-cases examined in this study were not treated according to the guidelines, and in $72 \%$ of these a physician, either GP or specialist, judged a drug falsely as not guideline recommended. In about the same proportion of cases, the patients stated that they did not know why they did not receive a drug recommended by the guidelines, indicating information deficits on the patient's side. Lack of awareness, lack of knowledge, overlooking values above target, or lack of communication, are possible underlying causes. On the other hand, about $30 \%$ of the QIs not fulfilled are due to various other reasons.

Our study points out that the improvement of guideline adherent care is far more than getting physicians to follow the guidelines. Patient information, patient involvement and the physician's willingness to inform and involve the patient are just as important. Finally, our study makes clear that $100 \%$ guideline-adherent care cannot be achieved due to e.g. adverse drug reactions and contraindications. Also, the deliberate decision of the patient not to take a particular drug must be respected.

\section{Abbreviations}

BP: Blood pressure; ACE-l: Angiotensin-converting enzyme inhibitor; ARB: Angiotensin receptor blocker; GP: General practitioner; CRF: Case report 
form; QI: Quality indicator; RAAS: Renin-angiotensin-aldosterone system; RAAS-I: Inhibitor of the renin-angiotensin-aldosterone system; RI: Renin inhibitor.

\section{Competing interests}

The authors declare that they have no competing interests, that there are neither support from any organisation for the submitted work, nor financial relationships with any organisations that might have an interest in the submitted work, nor other relationships or activities that could appear to have influenced the submitted work.

\section{Authors' contributions}

JF was the main researcher who collected the data, did the analysis of the data, and did the main research and writing. MF contributed to formatting, research and writing. AS designed the study and the CRF together with JF and participated in the writing process. All authors read and approved the final manuscript.

\section{Acknowledgments}

This study was carried out by the Institute of General Practice, Family Medicine and Preventive Medicine without any additional sponsoring. We would like to express our gratitude to all the participating physicians and patients of the province of Salzburg.

\section{Author details}

${ }^{1}$ Institute of General Practice and Family Medicine, University of Witten/ Herdecke, Alfred-Herrhausen-Str. 50, Witten 58448, Germany. ${ }^{2}$ Institute of General Practice, Family Medicine and Preventive Medicine, Paracelsus Medical University, Strubergasse 21, Salzburg 5020, Austria. ${ }^{3}$ Department of Evidence-based Medicine and Clinical Epidemiology, Danube University, Karl Dorrek-Straße 30, Krems 3500, Austria.

\section{Received: 3 August 2012 Accepted: 7 March 2013}

Published: 4 April 2013

\section{References}

1. EBM-Guidelines online. 2011. http://onlinelibrary.wiley.com/book/10.1002/ 0470057203

2. McGlynn EA, Asch SM, Adams J, Keesey J, Hicks J, DeCristofaro A, Kerr EA: The quality of health care delivered to adults in the United States. N Engl J Med 2003, 348:2635-2645.

3. Hoeks SE, op Reimer WJ S, van Gestel YR, Schouten O, Lenzen MJ, Flu WJ, van Kuijk JP, Latour C, Bax JJ, van Urk H, Poldermans D: Medication underuse during long-term follow-up in patients with peripheral arterial disease. Circ Cardiovasc Qual Outcomes 2009, 2:338-343.

4. Flamm M, Winkler H, Panisch S, Kowatsch P, Klima G, Furthauer B, Weitgasser R, Sönnichsen AC: Quality of diabetes care in Austrian diabetic patients willing to participate in a. Wien Klin Wochenschr 2011, 123:436-443.

5. DiMartino LD, Shea AM, Hernandez AF, Curtis LH: Use of guidelinerecommended therapies for heart failure in the Medicare population. Clin Cardiol 2010, 33:400-405.

6. Kedward J, Dakin L: A qualitative study of barriers to the use of statins and the implementation of coronary heart disease prevention in primary care. Br J Gen Pract 2003, 53:684-689.

7. Steinman MA, Patil S, Kamat P, Peterson C, Knight SJ: A taxonomy of reasons for not prescribing guideline-recommended medications for patients with heart failure. Am J Geriatr Pharmacother 2010, 8:583-594.

8. Safford MM, Shewchuk R, Qu H, Williams JH, Estrada CA, Ovalle F, Allison JJ: Reasons for not intensifying medications: differentiating "clinical inertia" from appropriate care. J Gen Intern Med 2007, 22:1648-1655.

9. $A B E$, Denig $P$, van $V T$, Dekker $J H$ : Reasons of general practitioners for not prescribing lipid-lowering medication to patients with diabetes: a qualitative study. BMC Fam Pract 2009, 10:24.

10. Lugtenberg M, Zegers-van Schaick JM, Westert GP, Burgers JS: Why don't physicians adhere to guideline recommendations in practice? An analysis of barriers among Dutch general practitioners. Implement Sci 2009, 4:54.

11. Cabana MD, Rand CS, Powe NR, Wu AW, Wilson MH, Abboud PA, Rubin HR: Why don't physicians follow clinical practice guidelines? A framework for improvement. JAMA 1999, 282:1458-1465.
12. Campbell SM, Reeves D, Kontopantelis E, Sibbald B, Roland M: Effects of pay for performance on the quality of primary care in England. $N$ Engl $J$ Med 2009, 361:368-378.

13. Lugtenberg M, Burgers JS, Besters CF, Han D, Westert GP: Perceived barriers to guideline adherence: a survey among general practitioners. BMC Fam Pract 2011, 12:98.

14. Alan D, Lopez A, MCEMea: Burden of Disease and Risk Factors, A copublication of Oxford University Press and The World Bank. 2006. doi:10.1596/978-0-8213-6262-4.

15. Dentali F, Douketis JD, Lim W, Crowther M: Combined aspirin-oral anticoagulant therapy compared with oral anticoagulant therapy alone among patients at risk for cardiovascular disease: a meta-analysis of randomized trials. Arch Intern Med 2007, 167:117-124.

16. Nicodeme R, Albessard A, Amar J, Chamontin B, Lang T: Poor blood pressure control in general practice: in search of explanations. Arch Cardiovasc Dis 2009, 102:477-483.

17. Chapman RH, Benner JS, Petrilla AA, Tierce JC, Collins SR, Battleman DS, Schwartz JS: Predictors of adherence with antihypertensive and lipidlowering therapy. Arch Intern Med 2005, 165:1147-1152.

18. Gazmararian JA, Kripalani S, Miller MJ, Echt KV, Ren J, Rask K: Factors associated with medication refill adherence in cardiovascular-related diseases: a focus on health literacy. J Gen Intern Med 2006, 21:1215-1221.

19. Britten N, Stevenson FA, Barry CA, Barber N, Bradley CP: Misunderstandings in prescribing decisions in general practice: qualitative study. BMJ 2000, 320:484-488.

20. Barratt A: Evidence Based Medicine and Shared Decision Making: the challenge of getting both evidence and preferences into health care. Patient Educ Couns 2008, 73:407-412.

21. Charles C, Gafni A, Whelan T: Decision-making in the physician-patient encounter: revisiting the shared treatment decision-making model. Soc Sci Med 1999, 49:651-661.

22. Sidorenkov G, Haaijer-Ruskamp FM, de ZD, Bilo H, Denig P: Review: relation between quality-of-care indicators for diabetes and patient outcomes: a systematic literature review. Med Care Res Rev 2011, 68:263-289.

doi:10.1186/1471-2296-14-47

Cite this article as: Fürthauer et al:: Patient and physician related factors of adherence to evidence based guidelines in diabetes mellitus type 2, cardiovascular disease and prevention: a cross sectional study. BMC Family Practice 2013 14:47.

\section{Submit your next manuscript to BioMed Central and take full advantage of:}

- Convenient online submission

- Thorough peer review

- No space constraints or color figure charges

- Immediate publication on acceptance

- Inclusion in PubMed, CAS, Scopus and Google Scholar

- Research which is freely available for redistribution 